\title{
Clinical and Angiographic Profile of Patients with Left Bundle Branch Block
}

\author{
Sahela Nasrin ', F. Aaysha Cader ${ }^{2}$, M. Maksumul Haq ${ }^{3}$
}

\begin{abstract}
Background \& objective: Left bundle branch block (LBBB), resulting in an alteration of the normal sequence of activation in the left ventricle, commonly occurs in patients with underlying heart disease particularly coronary artery disease (CAD), but it may also be associated with progressive conducting system disease in an otherwise structurally normal heart. The aim of this study was to evaluate the clinical and angiographic profile of patients presenting with LBBB.

Materials \& Methods: This study was a cross-sectional observational study. A total of 542 patients of LBBB (as evident by ECG) who underwent coronary angiography from $1^{\text {st }}$ September 2005 to $31^{\text {st }}$ August 2016 were identified from the records of Cath Lab database of Ibrahim Cardiac Hospital \& Research Institute and were selected for the study. LBBB was defined as a QRS complex duration $\geq 120 \mathrm{~ms}$ with a broad notched or slurred $\mathrm{R}$ wave in leads $\mathrm{I}, \mathrm{aVL}, \mathrm{V} 5$ and $\mathrm{V} 6$.

Results: Majority (95.8\%) of the patients was over 40 years of age with mean age being $59.7 \pm 10.7$ years (range: $25-95$ years). Nearly $60 \%$ of the patients were male, $62.2 \%$ diabetic and $69.7 \%$ hypertensive. Over one-third $(37.1 \%)$ of patients had moderate left ventricular (LV) systolic dysfunction (ejection fraction 30-44\%) and $7 \%$ had severe LV systolic dysfunction. Over half (51.9\%) had normal body mass index. Unstable angina $(45.8 \%)$ was the most common indication for angiography. Other indications included non-ST segment elevation myocardial infarction (17.2\%), ST segment elevation myocardial infarction $(11.3 \%)$, stable coronary artery disease (SCAD) $(9.8 \%)$, prior myocardial infarction (13.3\%) and atypical chest pain (2.6\%). Nearly $60 \%$ of the patients had obstructive coronary artery disease and the rest (40.6\%) had normal epicardial coronaries on angiography. Among those with obstructive CAD, $4.1 \%$ had left main disease, $20.5 \%$ had triple vessel disease (TVD), 14.4\% double vessel disease (DVD) and 9.5\% single vessel disease (SVD).

Conclusion: There is an optimum prevalence of CAD among LBBB patients, with TVD being predominant. LBBB cases with normal coronaries are no less. The latter cases suggest an alternative cause for LBBB. Thus, the usual diagnosis of CAD in patients with presumably new onset LBBB may be over-estimated in clinical practice.

Key words: Left bundle branch block (LBBB), clinical profile, angiographic profile.
\end{abstract}

\section{INTRODUCTION}

Left bundle branch block (LBBB) occurs due to interruption of normal electrical conduction through the left bundle of the His-Purkinje system, results in an alteration of the normal sequence of activation in the left ventricle..$^{1,2}$ It commonly occurs in patients with underlying heart disease and may be associated with progressive conducting system defect. However, LBBB can also be seen in asymptomatic patients with a structurally normal heart. The presence of LBBB complicates the diagnosis of myocardial ischemia/infarction and interferes with the interpretation of exercise testing. Specially new onset LBBB in the presence of chest pain is very much suggestive of acute

\section{Authors' information:}

${ }^{1}$ Dr. Sahela Nasrin, MBBS, MCPS (Med), MD (Card), Consultant \& Assistant Professor, Ibrahim Cardiac Hospital \& Research Institute (ICHRI), Dhaka.

${ }^{2}$ Dr. F. Aaysha Cader, MBBS, MRCP (UK), Registrar \& specialist Department of Cardiology, Ibrahim Cardiac Hospital \& Research Institute ICHRI, Dhaka.

${ }^{3}$ Prof. M. Maksumul Haq, MBBS, FCPS, FRCP, FACP, Professor \& Head, Department of Cardiology, Ibrahim Cardiac Hospital \& Research Institute (ICHRI), Dhaka.

Correspondence: Dr. Sahela Nasrin, Phone: +8801 766089094 E-mail:nasrin-jhumur@hotmail.com 
myocardial infarction (AMI). In patients with significant LV systolic dysfunction, LBBB results in left ventricular dyssynchrony and may contribute to heart failure. ${ }^{3}$

LBBB in asymptomatic subjects is generally associated with a good prognosis. ${ }^{4-6}$ But with advancing age, LBBB co-exists with underlying heart disease (e.g. ischaemic, hypertensive, or valvular) and acts as an independent predictor of poor cardiovascular outcomes. ${ }^{5,7-12}$ Thus, the incidental finding of LBBB is currently considered a potential marker of underlying heart disease, prompting further non-invasive or invasive diagnostic procedures. The objectives of this cros-sectional observational study was to find the prevalence of $\angle B B B$ with obstructive CAD, and LBBB with normal epicardial coronary artery as well as LBBB with variable left ventricular systolic function.

\section{MATERIALS \& METHODS:}

\section{Study population:}

We studied the records of all patients with LBBB (as evident by ECG) who underwent Coronary Angiogram (CAG) at our Cathlab. A total of 542 such patients were found who underwent CAG between $1^{\text {st }}$ September 2005 to $31^{\text {st }}$ August 2016 for various indications, like acute coronary syndrome, LBBB with shortness of breath, atypical chest pain and regional wall motion abnormality or global hypokinesia on echocardiography. The study was done complying with the Helsinki Declaration for Research Involving Human Subject, 2007. As the data were collected from hospital records of the patients with permission of the Hospital Ethics Committee, no new consent was needed to be taken from the patients or their legal guardians other than that for CAG. LBBB was defined as a QRS complex duration $\geq 120 \mathrm{~ms}$ with a broad notched or slurred $\mathrm{R}$ wave in leads $\mathrm{I}, \mathrm{aVL}, \mathrm{V} 5$ and V6, absence of Q waves in leads I, V5 and V6, aVR, peak time $>60 \mathrm{~ms}$ in leads $\mathrm{V} 5$ and $\mathrm{V} 6$ but normal in leads $V 1$ to $V 3$. Based on ejection fraction $(E F)$, systolic function was classified inton severe dysfunction( $E F<30 \%)$, moderate dysfunction ( $E F$ 30-44\%), mild dysfunction (EF 45-54\%) and normal (EF $\geq 55 \%)$.

\section{Image acquisition \& interpretation:}

Coronary angiography was done either by femoral or radial route. Diazepam and antihistamine were given orally as premedication in patients with history of allergy. If there was history of bronchial asthma, hydrocortisone in injectable form was given along with tablet ranitidine. Iodinated contrast medium was used. If the patient had chronic kidney disease, non-ionic, lower osmolality contrast agent (visipauqe) was used. Image interpretation was performed by two independent readers. Disagreement between readers was solved in Heart Team discussion regularly held in the Ibrahim Cardiac Hospital \& Research Institute (ICHRI). Coronary arteries were segmented according to a modified version of the American Heart Association 15-segment model which included the ramus intermedius, if present, as segment ${ }^{16}$. Each coronary segment was visually analysed with regard to the presence of stenosis and its severity as follows: no lesion, eccentric plaque ( $<30 \%$ diameter), mild lesion (30-49\% stenosis), moderate lesion (50-69\% diameter stenosis), severe stenosis (70-98\% stenosis), subtotal stenosis $(99 \%)$, or total occlusion (100\%). Obstructive CAD was defined as a stenosis $\geq 70 \%$ in at least one coronary segment or $\geq 50 \%$ in left main stem.

\section{RESULTS:}

Nearly half $(48.7 \%)$ of the patients was between 40-60 years and another half (47.1\%) was 60 or > 60 years old. Only $4.2 \%$ population was within the age range of 21 - 40 years. Mean age was 59.7 (range: 25-95) years. The patients were predominantly male $(59 \%)$ with male to female ratio being roughly 3:2 (Table I). The most common indication for angiography was unstable angina $(45.8 \%)$, followed by NSTEMI (17.2\%), prior MI (13.3\%), STEMI (11.3\%), stable coronary artery disease $(9.8 \%)$ and LBBB with atypical chest pain was (2.6\%) (Fig. 1). Systolic function evaluation, based on ejection fraction, showed that over one-third (37.1\%) of the patients had moderate LV systolic dysfunction, $26.6 \%$ had mild LV systolic dysfunction and $7 \%$ had severe dysfunction. (Table II). 
TABLE I: Age \& Sex distribution of patients with LBBB ( $n=542)$

\begin{tabular}{|c|c|c|}
\hline Age \& sex & Frequency & Percentage \\
\hline \multicolumn{3}{|l|}{ Age } \\
\hline$<40$ & 23 & 4.2 \\
\hline $40-60$ & 264 & 48.7 \\
\hline$\geq 60$ & 255 & 47.1 \\
\hline \multicolumn{3}{|l|}{ Sex } \\
\hline Male & 319 & 59.0 \\
\hline female & 223 & 41.0 \\
\hline
\end{tabular}

${ }^{*}$ Mean age $=59.7 \pm 10.7$ years and range $=(25-95)$.

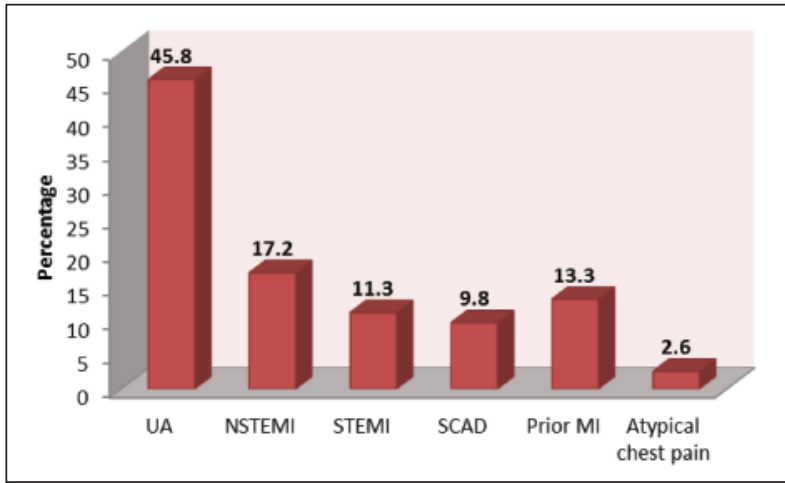

Fig: 1. Indication of CAG $(n=542)$

TABLE II: Distribution of EF in patients with LBBB $(n=542)$

\section{Systolic function}

Severe LV systolic dysfunction $(\mathrm{EF}<30 \%)$

Moderate LV systolic dysfunction (EF $=30-44 \%)$

Mild LV systolic dysfunction $(\mathrm{EF}=45-54 \%)$

Normal LV systolic function ( $\mathrm{EF} \geq 55 \%$ )

$\begin{array}{cr}\text { Frequency } & \text { Percentag } \\ 38 & 7.0 \\ 201 & 37.1 \\ 144 & 26.6 \\ 160 & 29.3\end{array}$

Clinical characteristics of the patients revealed that nearly $70 \%$ of the patients were hypertensive, $62.2 \%$ diabetic and $56 \%$ overweight or obese (35.6\% overweight, $10.7 \%$ obese) (Table III).

TABLE III: Clinical characteristics of patients with LBBB ( $n=542$ )

$\begin{array}{lcc}\text { Clinical characteristics } & \text { Frequency } & \text { Percentage } \\ \text { DM } & 337 & 62.2 \\ \text { HTN } & 378 & 69.7 \\ \text { BMI } & & \\ \quad \text { Under weight } & 11 & 2.0 \\ \text { Normal BMI } & 281 & 52.0 \\ \text { Over weight } & 193 & 35.6 \\ \text { Obese } & 57 & 10.4\end{array}$

${ }^{*}$ Mean age $=59.7 \pm 10.7$ years and range $=(25-95)$.
In terms of CAG, over $40 \%$ had normal or near normal angiographic findings, followed by TVD (20.5\%), DVD (14.4\%), SVD (9.5\%) \& LMS lesion $(4.1 \%)$. Patients with previous stenting and graft comprised $6.8 \%$ and $4.1 \%$ respectively (Fig. 2 ).

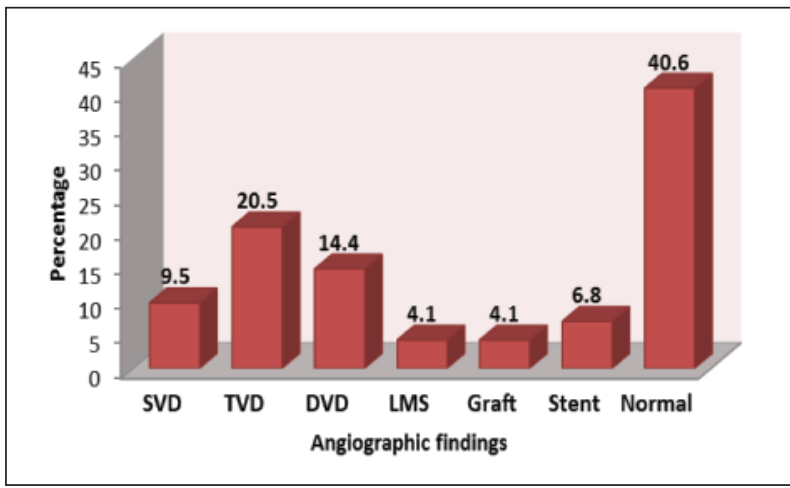

Fig: 2. Angiographic findings in patients with LBBB.

Over half (50.2\%) of the patients with obstructive CAD were advised to undergo PCI, 38.2\% were managed by medical treatment alone and $14 \%$ were advised to have CABG. Only $2.4 \%$ patients were advised for revascularization either by CABG or PCI (Fig: 3).

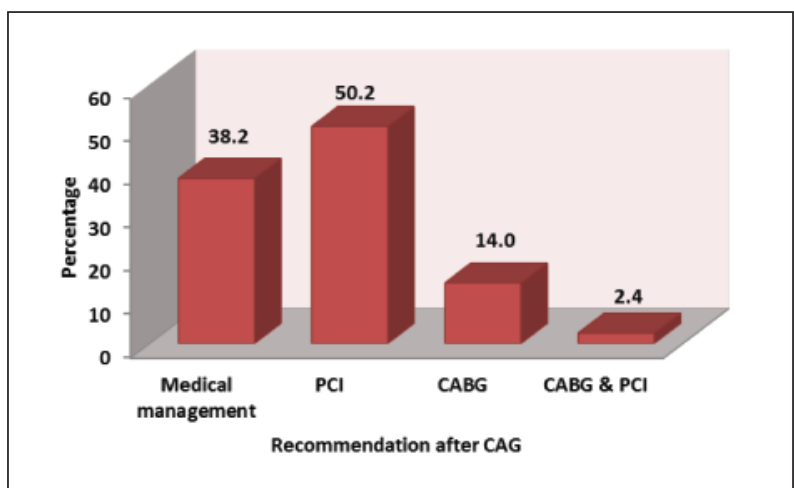

Fig: 3. Recommendation after CAG

\section{DISCUSSION:}

Important causes of LBBB are cardiomyopathy (both ischaemic and idiopathic), acute myocardial infarction, primary disease of the cardiac electrical conduction system, long standing hypertension and valvular disease, particularly aortic valve disease and myocarditis. Conventional coronary 
angiography is required most of the times to confirm diagnosis in patients with LBBB, as the non-invasive tests have limited utility. ${ }^{13-17}$

In our study, the prevalence of CAD in LBBB patients was $60 \%$, whereas the rest $40 \%$ were with normal angiographic findings. In a study conducted in Iran, the extent of CAD was assessed in 219 patients with LBBB who had undergone coronary angiography. Coronary artery disease was present in 124 (56.3\%) patients with LBBB. ${ }^{18}$ Abrol et al. studied 336 consecutive patients with LBBB referred for coronary angiography. Of them $54 \%$ had $C A D,{ }^{19}$ which compares well with that observed in our study. Prevalence of CAD was low in LBBB patients $(15 \%)$ as described by Olivier et al. ${ }^{20}$ The disparity of incidence in LBBB with our population was possibly due to the fact that our study population was heterogeneous, and included all the patients who underwent CAG including those with known CAD. However, Olivier et al ${ }^{20}$ excluded patients with known CAD to evaluate specifically the association of LBBB with unknown CAD. As we could not perform this selection, our results might have overestimated the prevalence of CAD in LBBB patients.

A substantial proportion of the study patients was hypertensive, which may be presumed to be an important cause of LBBB along with CAD. According to Framingham Heart Study acquired LBBB was associated with seven times higher risk of heart failure and two times higher risk of CAD. ${ }^{21}$

According to Olivier et $\mathrm{al}^{20}$ no significant differences were found with regard to CAD severity and number of diseased vessels. In our population among obstructive CAD, 20.5\% was TVD. Diabetics and overweight patients were also present in substantial proportions. However as our study was a descriptive cross-sectional study without a control group, we cannot conclusively consider these clinical characteristics as predictors of LBBB. Several case-control studies found no association between LBBB and CAD as described by Handerson et $\mathrm{al}^{6}$, which also holds true in our study, given that $40.6 \%$ of our population had normal or near normal angiographic findings. Echocardiography revealed mild to moderate LV systolic dysfunction in about two-thirds (63.7\%) of the cases which may also be a common feature of these patients.

The limitation of our study is that we included mostly those patients who underwent CAG for different indication like SCAD, prior MI, LBBB with poor EF, STEMI, NSTEMI. So the incidence of obstructive CAD was a bit higher than that of normal coronaries. Most previous studies $4,6-8,11,22$ performed their study with the CAD patients and LBBB and thus potentially overestimated the prevalence of CAD in LBBB cohorts.

Non-invasive assessment of CAD is challenging in the presence of LBBB, as the altered left ventricular activation combined with changes in functional perfusion frequently cause artefacts in imaging results, ${ }^{1,23}$ particularly in stress echocardiography. The stress echocardiography, SPECT, and PET are affected by $\angle B B B$, resulting in a reduced diagnostic accuracy. ${ }^{23,24}$ Cardiac magnetic resonance imaging is also affected by LBBB, but to a lesser extent if perfusion is assessed. ${ }^{25}$ In echocardiographic evaluation only $29 \%$ of our population had normal ejection fraction, whereas $\sim 40.5 \%$ of the subject had normal or near normal CAG findings. This contrast between echo and CAG indicates that the echo evaluation might have been affected by LBBB. Out of 542 patients, ${ }^{13}$ had idiopathic dilated cardiomyopathy, which also contributed to normal coronary angiography with EF less than 45\%. Valvular heart disease also constituted $4.2 \%$ of total LBBB patients. Four patients with CAD had ischaemic dilated cardiomyopathy with EF less than $35 \%$.

The objective of our study was to assess the prevalence of LBBB with CAD among patients who underwent for CAG with different indications. So from these findings we can conclude that some of our patients who were initially treated as CAD due to their presentation and ECG findings of LBBB, may not necessarily be patients of CAD. 
Angiography was done for these patients on the basis of symptoms. Some patients were devoid of florid symptoms but with wall motion abnormality in echocardiography and some with atypical symptoms with LBBB in ECG.

Moreover, a substantial proportion of our patients was diabetic and elderly, who can present with atypical symptoms and therefore might have underestimated the symptom. These patients particularly, require adequate assessment with CAG. Besides, our hospital being an enterprise of Bangladesh Diabetic Association, where we have to deal with a large number of diabetic population, who are unable to properly assess their ischemic symptoms.

Our sample was relatively large and included patients of both genders. Those patients having CAD were predominantly older males (60\%). They were more likely to have myocardial infarction $(\sim 28 \%)$, angina pectoris $(55.6 \%)$, diabetes mellitus (62.2\%) and reduced systolic function of left ventricle. So the findings of the present study and those of other investigators compared and contrasted above highlight the importance of early and aggressive evaluation in patients with LBBB.

\section{CONCLUSION:}

Our findings suggest that LBBB is not always associated with CAD. Some of the patients treated as CAD due to their presentation and ECG findings of LBBB may not have CAD. Thus, the prevalence of unknown CAD in patients with presumably new LBBB seems to be overestimated in everyday cardiologic practice. LBBB patients are generally older, overweight, hypertensive and diabetic with mild to moderate LV systolic dysfunction. Thus, decision to perform CAD testing in LBBB patients should rely on risk assessment using symptoms, demographics, and cardiovascular risk factors (CVRF), not solely on the presence of LBBB. If there is no definitive evidence like raised serum Troponin or CK-MB level or if the new onset LBBB is not associated with ischemic type of chest pain or shortness of breath we can consider other noninvasive procedures like coronary computed tomography angiography (CCTA) for further evaluation.

\section{REFERENCES:}

1. Kumar V, Venkataraman R, Aljaroudi W, Osorio J, Heo J, Iskandrian $A E$ et al. Implications of left bundle branch block in patient treatment. Am J Cardiol 2013;111:291-300.

2. Grines $\mathrm{CL}$, Bashore $\mathrm{TM}$, Boudoulas $\mathrm{H}$, Olson $\mathrm{S}$, Shafer $\mathrm{P}$, Wooley CF. Functional abnormalities in isolated left bundle branch block. The effect of interventricular asynchrony. Circulation 1989;79:845-53.

3. Sauer WH. Left bundle branch block. Cited November 30, 2017 available at: http://www.uptodate.com/contents/topic.do?topicKey $=$ CARD/914

4. Rotman $\mathrm{M}$, Triebwasser $\mathrm{JH}$. A clinical and follow-up study of right and left bundle branch block. Circulation $1975 ; 51: 477-84$.

5. Rabkin SW, Mathewson FA, Tate RB. Natural history of left bundle-branch block. Br Heart J 1980;43:164-9.

6. Hardarson T, Arnason A, Eliasson GJ, Palsson K, Eyjolfsson K, Sigfusson N. Left bundle branch block: prevalence, incidence, follow-up and outcome. Eur Heart J 1987;8:1075-9.

7. Rose G, Baxter PJ, Reid DD, McCartney P. Prevalence and prognosis of electrocardiographic findings in middle-aged men. Br Heart J 1978;40:636-43.

8. Schneider JF, Thomas HE Jr., Kreger BE, McNamara PM, Kannel WB. Newly acquired left bundle-branch block: the Framingham study. Ann Intern Med 1979;90:303-10.

9. Freedman RA, Alderman EL, Sheffield LT,Saporito M, Fisher LD. Bundle branch block in patients with chronic coronary artery disease: angiographic correlates and prognostic significance. J Am Coll Cardiol 1987;10: $73-80$.

10. Fahy GJ, Pinski SL, Miller DP, McCabe N, Pye C, Walsh MJ et al. Natural history of isolated bundle branch block. Am J Cardiol 1996;77:1185-90.

11. Imanishi R, Seto S,Ichimaru S, Nakashima E, Yano K, Akahoshi M. Prognostic significance of incident complete left bundle branch block observed over a 40-year period. Am J Cardiol 2006;98:644-8.

12. Zhang ZM, Rautaharju PM, Soliman EZ, Manson JE, Cain ME, Martin LW et al. Mortality risk associated with bundle branch blocks and related repolarization abnormalities (from the Women's Health Initiative [WHI]). Am J Cardiol 2012;110:1489-95.

13. Orzan F, Garcia E, Mathur VS \& Hall RJ. Is the treadmill exercise test useful for evaluating coronary artery disease in patients with complete left bundle branch 
block? Am J Cardiol 1978;42:36-40.

14. DePuey EG, Guertler-Krawczynska E \& Robbins WL. Thallium-201 SPECT in coronary artery disease patients with left bundle branch block. J Nucl Med 1988;29:1479-85.

15. Duncan AM, Francis DP, Gibson DG \& Henein MY. Differentiation of ischemic from nonischemic cardiomyopathy during dobutamine stress by left ventricular long-axis function: additional effect of left bundle-branch block. Circulation 2003; 108:1214-20.

16. Lebtahi NE, Stauffer JC \& Delaloye AB. Left bundle branch block and coronary artery disease: accuracy of dipyridamole thallium-201 single photon emission computed tomography in patients with exercise anteroseptal perfusion defects. J Nucl Cardiol 1997;4:266-73.

17. Geleijnse ML, Vigna C, Kasprzak JD, Rambaldi R, Salvatori MP, Elhendy A, et al. Usefulness and limitations of dobutamine-atropine stress echocardiography for the diagnosis of coronary artery disease in patients with left bundle branch block. A multicentre study. Eur Heart J 2000;21:1666-73.

18. Ghaffari S,Rajabi N, Alizadeh A \& Azarfarin R. Predictors of ventricular dysfunction and coronary artery disease in Iranian patients with Left bundle Branch Block. Int J Cardiol 2008;130(2):291-3.

19. Abrol R, Trost JC, Nguyen K, Cigarroa JE, Murphy SA, McGuire DK et al. Predictors of Coro $\neg$ nary Artery Disease in Patients With Left Bundle Branch Block Undergoing Coronary Angiography. Am J Cardiol 2006;98(10):1307-10.

20. Clerc OF, Possner M, Maire R, Liga R, Fuchs TA, Stehli
J et al. Association of left bundle branch block with obstructive coronary artery disease on coronary CT angiography: a case-control study. European Heart Journal Cardiovascular Imaging 2016;17:765-71. doi: 10.1093/ehjci/jev202.

21. Lee DS, , Gona P, Vasan PS, Larson MG, Benjamin EJ, Wang TJ ET AL. Relation Of Disease Etiology And Risk Factors To Heart Failure With Preserved Or Reduced Ejection Fraction. Insights From The National Heart, Lung, And Blood Institute's Framingham Heart Study. Circulation. 2009;119(24):3070-77. doi: 10.1161/CIRCULATIONAHA.108.815944.

22. Haataja $P$, Nikus $K$, Kahonen $M$, Huhtala $H$, Nieminen $T$, Jula $A$ et al. Prevalence of ventricular conduction blocks in the resting electrocardiogram in a general population: the Health 2000 Survey. Int J Cardiol 2013;167:1953-60.

23. Biagini $E$, Shaw LJ, Poldermans $D$, Schinkel AF, Rizzello $\mathrm{V}$, Elhendy A et al. Accuracy of non-invasive techniques for diagnosis of coronary artery disease and prediction of cardiac events in patients with left bundle branch block: a meta-analysis. Eur J NuCl Med Mol Imaging 2006;33:1442-51.

24. Koepfli P, Wyss CA, Gaemperli O, Siegrist PT, Klainguti M, Schepis $T$ et al. Left bundle branch block causes relative but not absolute septal under perfusion during exercise. Eur Heart J 2009;30:2993-9.

25. Mordi I, Stanton T, Carrick D, McClure J, Oldroyd K, Berry $C$ et al. Comprehensive dobutamine stress CMR versus echocardiography in LBBB and suspected coronary 